\section{Biodiversity in Switzerland}

SIR - The Swiss National Science Foundation (NF) recently funded a large (US\$3.5 million) biodiversity research programme. Oliver Klaffke, in the News article "Ecologists clash over too academic research" (Nature 368, 283; 1994), found that some ecologists from non-academic organizations in Switzerland were unhappy with the funding process for this programme and upset that most of the funds went to academic institutions for basic research. The article did not, however, discuss the original aims of the biodiversity programme, the scope of the current research or the relationship between basic and applied research. As co-authors or participants in five of the projects funded by the NF, we would like offer our views.

The initial call for proposals from the NF stated that the objectives of the biodiversity research programme were (1) to investigate the origins of biodiversity, especially of genetic diversity; (2) to study the dynamics of populations and the human influences on them; (3) to study the value of biodiversity; and (4) to evaluate strategies for the long-term conservation of biodiversity. Interdisciplinary, coordinated programmes were especially welcomed.

Twelve of the 20 funded projects were collectively designed by a 'diverse' group of scientists, mainly at the University of Basel, who developed a coordinated research programme to provide insights into the nature, maintenance and values of biodiversity ranging from the gene to ecosystem levels. The Basel scientists have chosen to concentrate their research at common grassland sites in the Jura Mountains, to share experimental infrastructure, and actively to exchange data. This group of scientists includes animal ecologists, biogeochemists, ecosystem modellers, evolutionary geneticists, meteorologists, plant population biologists and plant pathologists, as well as a lawyer concerned with legal means for the conservation of biodiversity. The two largest experiments in this programme seek to understand how two important human induced disturbances, habitat fragmentation and global change, will affect biodiversity. The goal of the habitat fragmentation study is to determine how genotypic and species diversity are affected by small-scale, experimental fragmentation in a species-rich, limestone grassland. These grasslands, like many other complex ecosystems, are becoming smaller and more isolated because of land use changes. Failure to understand the consequences of this fragmentation may lead to conservation strategies that fail to maintain biological diversity. The biodiversity $/ \mathrm{CO}_{2}$ study will help (1) to determine the role of biodiversity in ecosystem function and (2) to determine whether the future increases in atmospheric $\mathrm{CO}_{2}$ concentration will cause gene shifts within species, alter species dominance or lead to species extinctions. This study has been selected by an international board to be a core research project in the Global Change and Terrestrial Ecosystems programme of the International Geosphere-Biosphere Programme (Ambio 23, 74-76; 1994). The programme also includes studies of the generation of genetic diversity using microorganisms and the population dynamics of rare plant species. We firmly believe that such an integrated, experimental approach to understanding biodiversity is not "too academic". It is a prerequisite for successful management of biodiversity and for assessing its value.

John A. Arnone III

Plant Ecophysiology,

Michel Blot

Evolutionary Genetics,

Biozentrum,

Paul Leadley,

System Ecology,

Diethart Matthles

Plant Population Biology,

lan Sanders

Plant and Fungal Ecology,

University of Basel,

$\mathrm{CH}-4056$ Basel, Switzerland

\section{What next?}

SIR - What next - is Nature going to support an obligatory licence to ingest butter, bacon, beer or other allegedly harmful sustances subject to positive medical or other proof by licensee that the substances have not yet caused harm? Is Nature suggesting enforcement through permits and licences of recommended intake of calories, fat, sugar and salt? Should people be force-fed optimal foodtablets and otherwise restricted to reduce their perceiving personal risks?

Are prohibition, rationing and/or licensing of "tobacco (cannabis)" and the like, which mainly cause harm to voluntary consumers of them, Nature's choice of tools to regulate the quality of life of intelligent citizens in free societies? And is Nature contemplating sanctions (the severity of which I dare not consider) for the wrong-doers?

Knowing Nature, I would be surprised, but reading "When will cigarettes be smoked out?" (Nature 369, 691-2; 1994), one can but wonder.

\section{Christian Hansen}

Østerbrogade 118, 3. tv,

DK-2100 Copenhagen,

Denmark

\section{Backward step}

SIR - The 1994 meeting of the British Association is nearly upon us.

It is for the advancement of science, a subject that involves many facts as well as methods, hypotheses, concepts and opinions, a subject in which newly discovered results and ideas usually need to be related to old ones in order to be understood. For example, it makes little sense to seek to explain what a Higgs boson is, if not the sociology of why we should search for one, to someone who has only a hazy notion of an atom and no notion of an electron.

These thoughts prompt the suggestion of two gedanken experiments. Let all the lectures at the 1993 British Association meeting, except those by Messrs Lawson and Waldegrave, be repeated at the 1994 meeting. How many of those attending would be aware of the repetition?

Another experiment would be to examine orally all those who have read last year's explanations of the Higgs boson. What would their average grade be?

I am pessimistic about the results of these experiments because the dilemma of making science widely intelligible and widely attractive is so difficult to resolve. It does science and the nation a disservice to underestimate the difficulty of resolving the dilemma.

\section{Phillp Drazin}

University of Bristol,

School of Mathematics,

University Walk, Bristol BS8 1TW, UK

\section{Cancer trials}

SIR - In your News story on the breast cancer prevention trials (Nature 369, 516; 1994) you state that the Imperial Cancer Research Fund (ICRF) is recruiting women for the UK trial. In fact the UK trial is run by the United Kingdom Coordinating Committee on Cancer Research and women are recruited by the trial coordinator and by the participating centre, not the ICRF. The ICRF's role is, together with the Cancer Research Campaign, to provide the funding for the trial.

\section{Jean Mossman}

United Kingdom Co-ordinating

Committee on Cancer Research,

PO Box 123, Lincoln's Inn Fields,

London WC2A 3PX, UK

\section{Correction}

SIR - In "Delaney and cancer" (Nature $368,580 ; 1994)$, lines $41-42$ should read "9 $\times 10^{18}$ molecules" as originally published in reference 3 , rather than $9 \times 10^{10}$.

Thomas H. Jukes

Department of Integrative Biology,

University of California, Berkeley,

Oakland, California 94008, USA 